\title{
A State Chapter Perspective on Burnout and Resiliency
}

Donald O. Mack, MD, FAAFP, AGSF, CMD

In the article, "Burnout in Young Family Physicians: Variation Across States"1, the authors reviewed and surveyed diplomates of the American Board of Family Medicine (ABFM) in 2016, after 3 years in practice. The rates of emotional exhaustion and depersonalization, 2 components of burnout, from 23 states, reveal significant variation by state and further variation between the 2 components within states. A previous study of all recertifying ABFM diplomates in 2016 found that $24.5 \%$ reported symptoms of burnout. ${ }^{2}$ However, physicians in their 30s had the highest overall rate with female physicians being particularly prone to burnout. The current study focused solely on this group of new physicians, demonstrating significant variation behind the averages. Understanding why the emotional exhaustion varies 3-fold between Michigan and South Carolina will be important to keep young family physicians engaged in the workforce and keeping their patients healthy. State chapters, such as the Ohio Academy of Family Physicians (OAFP), are now talking about burnout, developing more resources for wellness, and advocating for strategies to decrease physician administrative burdens.

Increasingly, the effects of burnout and the concern for physicians' mental health are the topics of articles, presentations, and studies. Family physicians are not immune, and according to the State of Family Medicine in 2017, 63.0\% of family physi-

From Wexner Medical Center, Department of Family Medicine, Ohio State University, Columbus, OH.

Funding: none.

Conflict of interest: none declared.

Corresponding author: Donald O. Mack, MD, FAAFP, AGSF, CMD, Wexner Medical Center Department of Family Medicine, 207 Northwood \& High Building, 2231 N. High Street, Columbus, OH, 43201 (E-mail: donald.mack@osumc.edu).

\section{See Related Article on Page 7.}

cians meet the criteria for burnout compared with $54.4 \%$ of all physicians. ${ }^{3}$ It is also concerning that physicians have higher rates of emotional exhaustion, depersonalization, and overall burnout compared with other US workers, and that physicians had a $10 \%$ increase in burnout from 2011 to 2014 , whereas other US workers showed no increase. ${ }^{4}$ It is not surprising that this study also noted that physicians worked a median of 10 hours more per week than other US workers, and that $41.8 \%$ of the physicians and only $6.4 \%$ of the US worker controls, worked 60 hours or more per week. ${ }^{4}$

It is critical to study more fully the causes of these trends in physician burnout. Burnout is associated with lower patient satisfaction and care quality, higher medical error rates and malpractice risk, higher physician and staff turnover, physician substance abuse/addiction, and physician suicide. ${ }^{5}$ The causes are numerous, and in many cases physicians point to the increasing demands of electronic medical records, quality metrics, administrative tasks such as prior authorization, and value-based payment requirements, which take time away from direct clinical care. Physicians enter medicine focused on patients, but one study notes that ambulatory physicians spend less than one third of their time in direct clinical care. ${ }^{6}$ Although new physicians usually have fresh experience and skills from their training program in avoiding burnout, they often have additional stressors of relocation, adaptation to a new practice setting, financial adjustments of increased income/debt repayment, and "catch up" on personal and family obligations after navigating medical school and residency.

Current efforts call for physicians to increase resiliency with the anticipated gain of providing better care, committing fewer errors, and sustaining a healthy practice. ${ }^{7}$ At the same time, Rebekah Bernard $^{8}$, a family physician, stresses that physicians have been too "resilient" creating this current fiasco. Her premise is that physicians desire to care 
for patients more than run a practice, and by doing so, have allowed others to take over the financial management. She goes further to explain that physicians have accepted increasing tasks of checking boxes, and completing even more administrative tasks to improve practice metrics with the end result that physicians are now working for practice managers rather than patients. ${ }^{8}$ Bernard is not alone in the frustration with the fee-for-service system, and many family physicians are now practicing direct primary care (DPC), as an alternative. This allows physicians to stop the many administrative tasks inherent to the fee for service system and value-based payment programs. Family physicians can manage these reduced management requirements and focus on patient care while patients pay a monthly retainer that covers all or most primary care services. Family physicians practicing DPC note an improved sense of autonomy, more control in their practice, and at the same time spend more time doing patient care.

At our core, family physicians solve puzzles every day, and seek to improve the health of our patients and our colleagues. The differences in the rates of emotional exhaustion and depersonalization between new physicians in various states as noted in the study ${ }^{1}$, will likely provide clues as research pursues future answers. Family physicians and especially new family physicians will not have to do this work alone. State chapters and the American Academy of Family Physicians will continue to be on the frontline for our members, examining the causes of burnout, and opportunities to augment resiliency. The OAFP even has a Joy of Medicine Workgroup to bring joy back to the practice of family medicine, identify strategies for physician self care, promote supportive peer networks, provide leadership and mentoring opportunities, and foster a culture of positivity and professional satisfaction. It is what we do.

The author thanks Lars Peterson, $\mathrm{MD}, \mathrm{PhD}$, for his contribution as a reviewer and providing valuable feedback.

\section{References}

1. Hansen A, Peterson LE, Fang B, Phillips RL. Burnout in young family physicians: Variation across states. J Am Board Fam Med 2017;31:7-8.

2. Puffer JC, Knight HC, O'Neill TR, et al. Prevalence of burnout in board certified family physicians. J Am Board Fam Med 2017;30:125-6.

3. White B, Twiddy D. The State of Family Medicine: 2017. Fam Pract Manag 2017;24:26-33.

4. Shanafelt TD, Hasan O, Dyrbye LN, et al. Changes in burnout and satisfaction with work-life balance in physicians and the general US working population between 2011 and 2014. Mayo Clin Proc 2015;90: $1600-13$.

5. Drummond D. Physician burnout: Its origin, symptoms, and five main causes. Fam Pract Manag 2015; $22: 42-47$.

6. Sinsky C, Colligan L, Li L, et al. Allocation of physician time in ambulatory practice: A time and motion study in 4 specialties. Ann Intern Med 2016; 165:753-60.

7. Epstein RM, Krasner MS. Physician resilience: What it means, why it matters, and how to promote it. Acad Med 2013;88:301-3.

8. Bernard R. To prevent burnout, physicians need less resilience, not more. (2016, September 13). Available from: http://www.kevinmd.com/blog/2016/09/ prevent-burnout-physicians-need-less-resiliencenot.html. Accessed November 11, 2017. 